Article

\title{
High Sensitive and Selective Sensing of Hydrogen Peroxide Released from Pheochromocytoma Cells Based on Pt-Au Bimetallic Nanoparticles Electrodeposited on Reduced Graphene Sheets
}

\section{Guangxia Yu, Weixiang Wu, Xiaoqi Pan, Qiang Zhao, Xiaoyun Wei and Qing Lu *}

Key Laboratory of Environment and Health, Ministry of Education \& Ministry of Environmental Protection, and State Key Laboratory of Environmental Health (Incubating), School of Public Health, Tongji Medical College, Huazhong University of Science and Technology, Wuhan 430030, China; E-Mails: yu266021@163.com (G.Y.); sam_woo123@foxmail.com (W.W.); xiaoqipan0913@163.com (X.P.); farutong@163.com (Q.Z.); weixiaoyun2046@163.com (X.W.)

* Author to whom correspondence should be addressed; E-Mail: luqing@hust.edu.cn; Tel.: +86-27-8362-5912; Fax: +86-27-8365-7765.

Academic Editor: W. Rudolf Seitz

Received: 18 November 2014 / Accepted: 19 January 2015 / Published: 26 January 2015

\begin{abstract}
In this study, a high sensitive and selective hydrogen peroxide $\left(\mathrm{H}_{2} \mathrm{O}_{2}\right)$ sensor was successfully constructed with Pt-Au bimetallic nanoparticles (Pt-Au NPs)/reduced graphene sheets (rGSs) hybrid films. Various molar ratios of $\mathrm{Au}$ to $\mathrm{Pt}$ and different electrodeposition conditions were evaluated to control the morphology and electrocatalytic activity of the Pt-Au bimetallic nanoparticles. Upon optimal conditions, wide linear ranges from $1 \mu \mathrm{M}$ to $1.78 \mathrm{mM}$ and $1.78 \mathrm{mM}$ to $16.8 \mathrm{mM}$ were obtained, with a detection limit as low as $0.31 \mu \mathrm{M}$. Besides, due to the synergetic effects of the bimetallic NPs and rGSs, the amperometric $\mathrm{H}_{2} \mathrm{O}_{2}$ sensor could operate at a low potential of $0 \mathrm{~V}$. Under this potential, not only common anodic interferences induced from ascorbic acid, uric acid and dopamine, but also the cathodic interference induced from endogenous $\mathrm{O}_{2}$ could be effectively avoided. Furthermore, with rat pheochromocytoma cells (PC 12) as model, the proposed sensor had been successfully used in the detection of $\mathrm{H}_{2} \mathrm{O}_{2}$ released from the cancer cells. This method with wide linear ranges and excellent selectivity can provide a promising alternative for $\mathrm{H}_{2} \mathrm{O}_{2}$ monitoring in vivo in the fields of physiology, pathology and diagnosis.
\end{abstract}


Keywords: hydrogen peroxide sensor; bimetallic nanoparticles; reduced graphene sheets, electrocatalysis; cancer cells; oxidative stress

\section{Introduction}

$\mathrm{H}_{2} \mathrm{O}_{2}$ is an indicator of oxidative stress [1], which is closely related to the physiological and pathological events such as aging, cancer, ischemia/reperfusion injury, traumatic brain injury, impaired learning and memory functions, and so on [2,3]. In view of the importance of $\mathrm{H}_{2} \mathrm{O}_{2}$, development of real-time monitoring strategies for $\mathrm{H}_{2} \mathrm{O}_{2}$ in vivo, which can enable researchers to understand the chemical nature of oxidative stress in these physiological and pathological events, has aroused great attention in recent years. Several analytical technologies have been described for $\mathrm{H}_{2} \mathrm{O}_{2}$ determination in cellular environments, including spectrophotometry [4], electrochemical sensors [5], fluorimetry [6] and automatic potential titration [7]. Among these methods, amperometric techniques have attracted more and more attention in biological applications recently on account of their merits including excellent temporal resolution for measurements as well as great potential to image the dynamic release process of $\mathrm{H}_{2} \mathrm{O}_{2}$ [8]. Additionally, amperometric methods can also provide much more precise kinetic information on the exocytotic process itself and allow the efficiency evaluation of the whole process in real-time [9].

However, when employed for practical applications, $\mathrm{H}_{2} \mathrm{O}_{2}$ sensors are still up against primary challenges including high selectivity and wide linear range of the determination. On the one hand, within the biological environments, glucose, uric acid (UA), ascorbic acid (AA), dopamine (DA) as the anodic interferents and the endogenous oxygen as the cathodic interferent are usually co-existence with $\mathrm{H}_{2} \mathrm{O}_{2}$ [10]. Consequently, high selectivity is essential during the detection of $\mathrm{H}_{2} \mathrm{O}_{2}$ in the cellular environments. On the other hand, $\mathrm{H}_{2} \mathrm{O}_{2}$ holds a rather low concentration under normal physiological conditions while the concentration of $\mathrm{H}_{2} \mathrm{O}_{2}$ may increase to $10^{-3} \mathrm{~mol}$ under pathological conditions such as suffering ischemia/reperfusion injury or cancers [11]. Thus, it is necessary to conduct quantitative measurements for $\mathrm{H}_{2} \mathrm{O}_{2}$ with a broad linear range to figure out the role that $\mathrm{H}_{2} \mathrm{O}_{2}$ plays in physiological and pathological processes.

During the recent decades, bimetallic nanoparticles have been applied for the detection of $\mathrm{H}_{2} \mathrm{O}_{2}$ [12]. Compared with the corresponding monometal nanoparticles, bimetallic possesses higher catalysis, better resistance to deactivation, and greater selectivity [13]. Tsai et al. [14] fabricated electrochemical sensor based on the Au-Ag alloy nanoparticles, which exhibited high sensitivity and good selectivity for $\mathrm{H}_{2} \mathrm{O}_{2}$. Niu et al. [15] proposed novel snowflake-like Pt-Pd bimetallic clusters modified screenprinted gold nanofilm electrode for $\mathrm{H}_{2} \mathrm{O}_{2}$ and glucose sensing. In addition, bimetallic nanoparticles such as $\mathrm{Pt} / \mathrm{Ag}$ and $\mathrm{Pt} / \mathrm{Cu}$ [16], $\mathrm{Pt} / \mathrm{Pd}$ [17], $\mathrm{Pd} / \mathrm{Cu}$ [18], $\mathrm{Rh} / \mathrm{Pd}$ [19] and $\mathrm{Ru} / \mathrm{Rh}$ [20] were applied for constructing an electrochemical platform for determination of $\mathrm{H}_{2} \mathrm{O}_{2}$, and most of them possessed great potential.

Reportedly, platinum nanoparticles (Pt NPs) exhibit good electrocatalytic behaviors towards hydrogen peroxide and have been extensively used for $\mathrm{H}_{2} \mathrm{O}_{2}$ reduction at negative potentials [21], which can easily avoid the anodic interferents like AA, UA. However, Pt NPs modified electrodes could suffer 
from poor limit of detection and unstable baseline in most cases. Moreover, the cathodic interference of $\mathrm{O}_{2}$ is hard to be averted on account of its exceedingly negative reduction potential. Found from bimetal researches, the addition of a second metal, such as $\mathrm{Au}$, could greatly improve the electrocatalytic and sensing performance of $\mathrm{Pt}$, owing to the unique electrochemical properties of $\mathrm{Au}$ NPs as well as its ability to protect Pt from being poisoned by the reduction intermediates [22]. In the recent years, reduced graphene sheets have attracted a great deal of attention due to their high specific surface area, excellent electronic conductivity, and high-chemical stability [23], which can improve the electrocatalytic activity and provide more active site for the anchoring of substrate [24].

In this study, a novel $\mathrm{H}_{2} \mathrm{O}_{2}$ sensor based on Pt-Au/rGSs/GCE was fabricated by cyclic voltammetry method using the surfactant Brij 58 as a soft template. The results had indicated the addition of Au and rGSs could effectively improve the electrocatalytic properties and stability of Pt towards the reduction of $\mathrm{H}_{2} \mathrm{O}_{2}$. The proposed $\mathrm{H}_{2} \mathrm{O}_{2}$ sensor, possessing high sensitivity, excellent selectivity, good reproducibility and long-term stability, had been proven to be promising for the practical application in the real-time monitoring of $\mathrm{H}_{2} \mathrm{O}_{2}$ in vivo.

\section{Experimental Section}

\subsection{Reagents}

$\mathrm{H}_{2} \mathrm{PtCl}_{6} \cdot 6 \mathrm{H}_{2} \mathrm{O}, \mathrm{HAuCl}_{4} \cdot 3 \mathrm{H}_{2} \mathrm{O}$, Brij 58 , catalase and lipopolysaccharide (LPS) were obtained from Sigma Aldrich (Shanghai, China). $\mathrm{H}_{2} \mathrm{O}_{2}(30 \%)$ was purchased from Sinopharm Chemical Reagent Co. Ltd (Shanghai, China). The reduced graphene sheets were obtained by the reduction of graphite oxide (obtained from Alfa Aesar, Ward Hill, MA, USA) via a chemistry synthetic route involving ultrasonic exfoliation and chemical reduction [25]. PC 12 cells were obtained from Chinese Academy of Sciences cell bank. All the other reagents were of analytical grade and double-distilled water was applied for all the aqueous solutions.

\subsection{Apparatus}

Electrochemical measurements were carried out employing a conventional three-electrode system, consisting a bare or modified glass carbon electrode with diameter $3 \mathrm{~mm}$ as the working electrode, a saturated calomel electrode (SCE) as the reference electrode and a platinum wire as the counter electrode. The cyclic voltammetry $(\mathrm{CV})$ and current-time measurements were performed on a CHI830C electrochemical workstation (Shanghai Chenhua Apparatus, China). Field emission scanning electron microscopy (FESEM) and X-ray energy dispersive spectrometer (EDS) were taken at a Sirion 200 field-emission scanning electron microanalyzer with EDAX energy disperse spectroscopy (FEI, Netherlands). The morphology of the samples was characterized using high resolution transmission electron microscopy HRTEM (JEM-2100F, JEOL, Tokyo, Japan) equipped with selected area electron diffraction (SAED). The phase structures of the samples were determined by X-ray diffraction (XRD) (X'Pert Pro; Cu K $\alpha, \lambda=0.1542$ nm, Philips, Amsterdam, The Netherlands). 


\subsection{Preparation of Pt-Au/rGSs Modified Electrode}

GCE was polished with $0.05 \mu \mathrm{m}$ alumina slurry, and then sonicated successively in nitric acid (1:1), ethanol and twice-distilled water. After that, $5 \mu \mathrm{L}$ of $1 \mathrm{mg} \cdot \mathrm{mL}^{-1} \mathrm{rGSs}$ suspension was pipetted onto the GCE surface and dried under an infrared lamp to obtain $\mathrm{rGSs} / \mathrm{GCE}$. Thin Pt-Au alloy film was deposited on $\mathrm{rGSs} / \mathrm{GCE}$ by cyclic voltammetry method in the aqueous solution of $2 \mathrm{mM}$ $\mathrm{H}_{2} \mathrm{PtCl}_{6} \cdot 6 \mathrm{H}_{2} \mathrm{O}$ and $1 \mathrm{mM} \mathrm{HAuCl}{ }_{4} \cdot 3 \mathrm{H}_{2} \mathrm{O}$ with $1.0 \mathrm{wt} \%$ Brij 58 under the potential from $0.4 \mathrm{~V}$ to $-0.5 \mathrm{~V}$ at the scan rate of $100 \mathrm{mV} \cdot \mathrm{s}^{-1}$ for five cycles. After the deposition, the film was rinsed with double-distilled water and then dried at room temperature for further use.

\subsection{Detection of $\mathrm{H}_{2} \mathrm{O}_{2}$ Released from $\mathrm{PC} 12$ Cells}

The PC 12 cells were maintained in Roswell Park Memorial Institute (RPMI-1640) medium containing $10 \%$ fetal bovine serum, $100 \mathrm{unit} \cdot \mathrm{mL}^{-1}$ penicillin, and $100 \mu \mathrm{g} \cdot \mathrm{mL}^{-1}$ streptomycin. In the proliferative period, cells were cultured at $37{ }^{\circ} \mathrm{C}$ with $5 \% \mathrm{CO}_{2}$ for about $24 \mathrm{~h}$. Then, the cells were centrifuged to obtain a cell-packed pellet $\left(1.0-2.0 \times 10^{5}\right.$ cells $\left.\cdot \mathrm{cm}^{-2}\right)$ for the electrochemical experiments. Cell counting was carried out under a microscope. And real sample measurements were performed in PBS containing $100 \mathrm{mM}$ glucose.

\section{Results and Discussion}

\subsection{Characterizations of the Pt-Au/rGSs Hybrid Films}

The morphology and the structure of the Pt-Au/rGSs hybrid films were characterized by the FESEM and TEM measurements. As shown in Figure 1A, the typical FESEM image of Pt-Au/rGSs hybrid films and the as-prepared Pt-Au NPs with approximately $100 \mathrm{~nm}$ in diameter were found to be well dispersed on the graphene sheets. In these hybrid films, rGSs could support large surface areas for the deposition of nanoparticles. Thus, nanoparticles could be highly dispersed through the deposition on the both sides of these rGSs supports which could significantly improve the catalytic activity and sensors sensitivity as reported [26,27]. From the TEM image in Figure 1B, fluffy texture and irregular mesopores could be directly observed on the external surface of the Pt-Au particles, which might facilitate the charge-transfer and mass-transfer processes.

In addition, the HRTEM, SADE and XRD were employed to further determine the crystalline phase and chemical composition of the Pt-Au NPs. In Figure 1C, the HRTEM image revealed the lattice fringes of the NPs with interplanar spacing of $0.231 \mathrm{~nm}$ and $0.199 \mathrm{~nm}$ were in consistent with the (111) and (200) planes of Pt-Au alloy. In addition, the corresponding selected area electron diffraction (SAED) pattern (Figure 1D) indicated the polycrystalline nature of the NPs, and the diffraction rings could be readily indexed to the (111), (200), (220) and (311) planes of the Pt-Au alloy phases, demonstrating a face-centered cubic (fcc) structure. Furthermore, as shown in Figure 1E, XRD patterns of (a) bare glassy carbon slices (GCS) and (b) Pt-Au/rGSs modified on the GCS were recorded in the $2 \theta$ range of $15-80^{\circ}$. Several peaks were observed in the patterns of bare GCS which were due to the $\mathrm{C}$ element contained in GCS. In the case of Pt-Au/rGSs, two new peaks were observed. The peaks at $26.6^{\circ}$ arose from the (003) plane of graphite in the rGSs. Besides, as shown by the dashed line, the 
(111) peak of Pt-Au/rGSs $\left(39.03^{\circ}\right)$ located between that of $\mathrm{Pt}\left(39.76^{\circ}\right)$ and $\mathrm{Au}\left(38.18^{\circ}\right)$ could further confirm the formation of the Pt-Au alloy. The elemental composition in Pt-Au/rGSs was analyzed via EDS (Figure 1F). The atomic number ratio of Au to Pt in the NPs film was 41.5:58.5, which was larger than the ratio in the precursor (with gold to platinum mole ratio of 1:2). The phenomenon could be attributed to the higher growth speed of the Au species than the Pt species under the provided electrodeposition conditions [28].
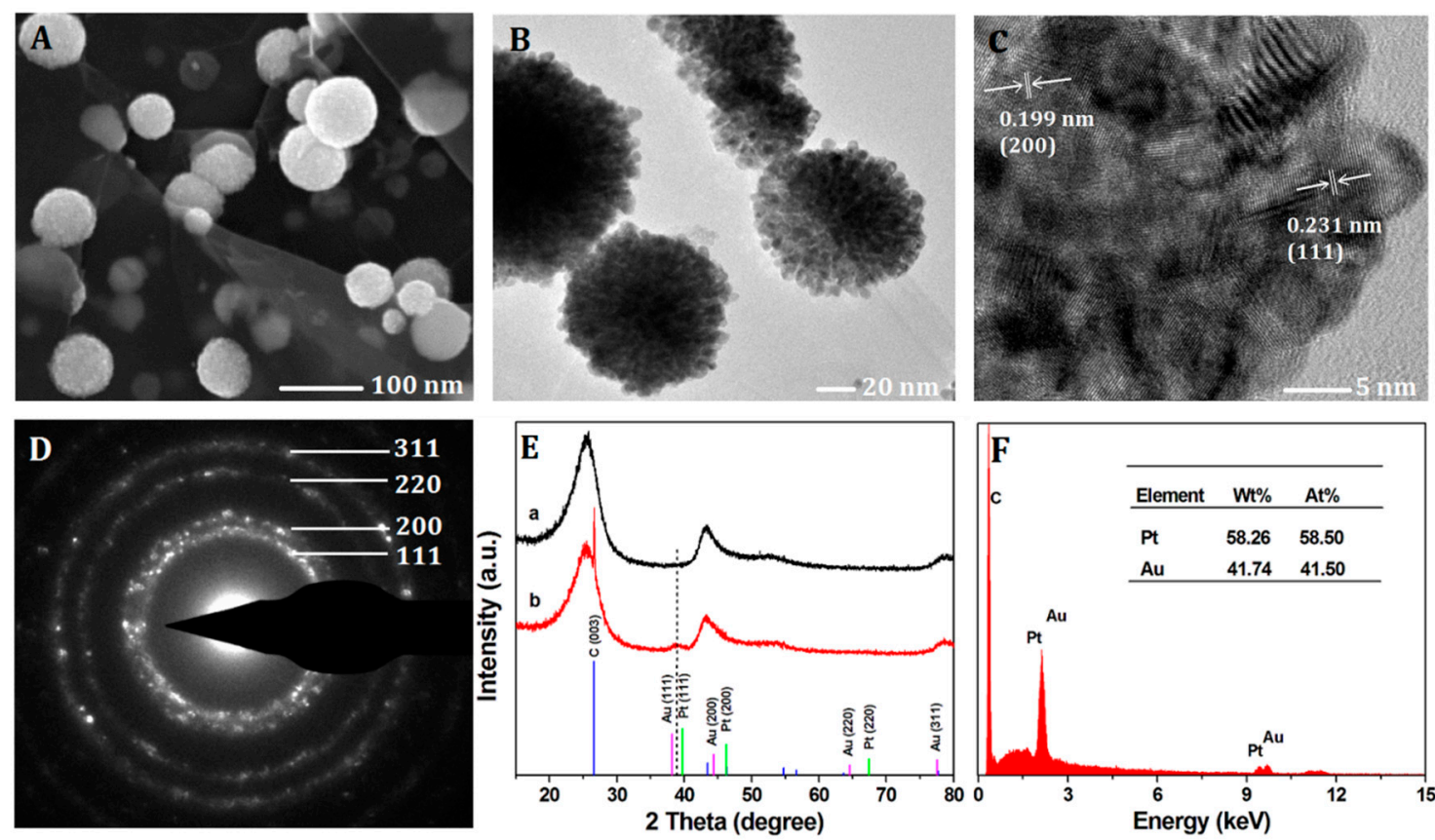

Figure 1. (A) FESEM image; (B) TEM image; (C) HRTEM image and (D) the corresponding SAED pattern of the Pt-Au/rGSs; (E) XRD patterns of (a) blank glassy carbon slice and (b) Pt-Au/rGSs modified on the glassy carbon slice; (F) EDS spectrum of the Pt-Au/rGSs.

\subsection{Optimization Parameters of the Pt-Au NPs Electrodeposition}

Various molar ratios of $\mathrm{Au}$ to $\mathrm{Pt}\left(\mathrm{Au}^{3+} / \mathrm{Pt}^{4+}=0,0: 1,1: 4,1: 2,1: 1\right.$ and 1:0) had been employed for the preparation of Pt-Au alloy film in the study. The FESEM images of Pt-Au alloy film were shown in Figure 2. When there were only Pt species dissolved in the solution, very little NPs were deposited on the reduced graphene sheets. After the addition of Au species, much more uniform NPs were highly dispersed on the rGSs supports. However, when there were only Au species, as shown in Figure 2C, the NPs aggregated. The phenomenon could be attributed to the fact that the Au species, unlike Pt, tended to grow rapidly. The high-growth speed of $\mathrm{Au}$ species might be responsible for the NPs aggregating [28]. The effect of the ratio on the catalytic activity for $\mathrm{H}_{2} \mathrm{O}_{2}$ reduction was also evaluated. The results depicted in Figure 2D had indicated that the peak current of $\mathrm{H}_{2} \mathrm{O}_{2}$ increased significantly with the increase of $\mathrm{Au}^{3+}$ compositional ratio and achieved a maximum at the ratio up to 0.5 Then the current decreased as the compositional ratio further increased. The reason of the phenomenon might be that as the $\mathrm{Au}$ compositional ratio increased in the precursor solution, more homogeneous nanoparticles could be well distributed on the rGSs modified electrode, resulting in a larger surface 
area. Under this circumstance, the electrocatalytic activity of the alloy film to $\mathrm{H}_{2} \mathrm{O}_{2}$ was greatly improved. However, with the gradual increase of the Au ratio, the nanoparticles would aggregate, leading to the reduction of the catalytic active sites and the decrease of the electron transfer ability. Thus, 0.5 was chosen as the optimal Au compositional ratio for further study.
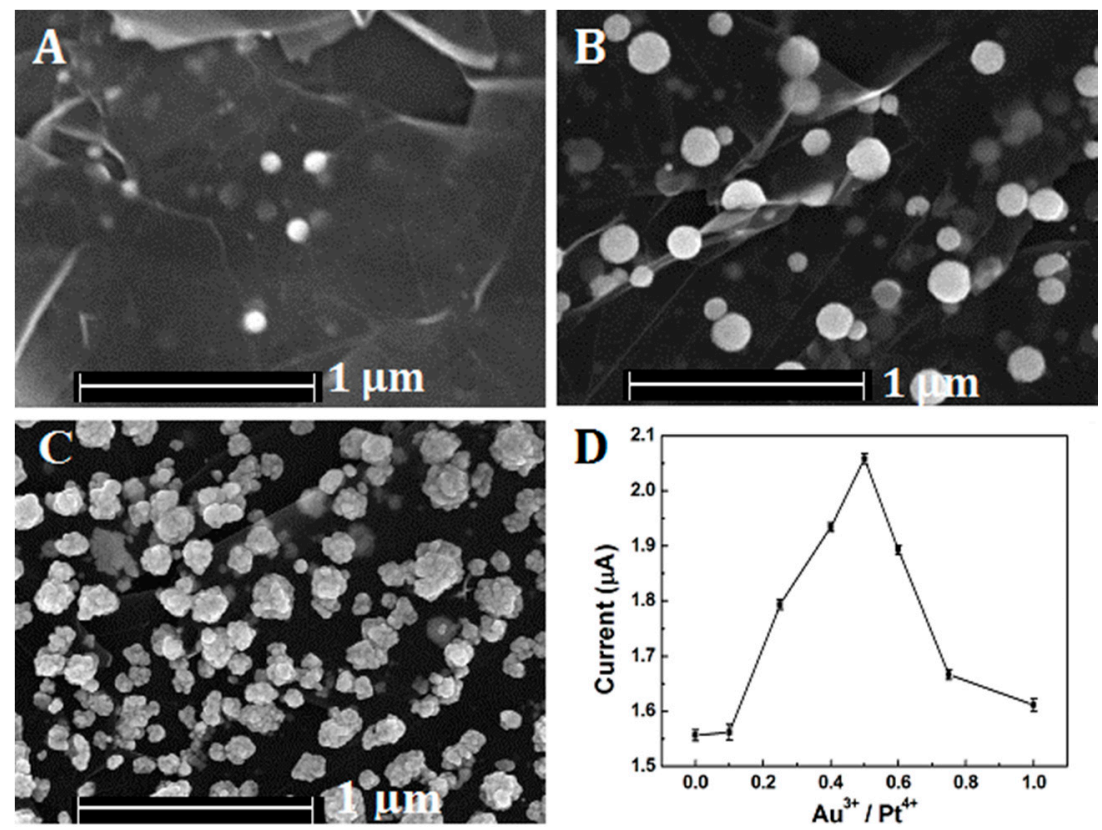

Figure 2. FESEM images of Pt-Au/rGSs hybrid films with different compositional ratios: $\mathrm{Au}^{3+} / \mathrm{Pt}^{4+}=$ (A) $0: 1$, (B) $1: 2$ and (C) $1: 0$; (D) plots of the peak current for the $\mathrm{Pt}-\mathrm{Au} / \mathrm{rGSs} / \mathrm{GCE}$ in the presence of $0.1 \mathrm{mM} \mathrm{H}_{2} \mathrm{O}_{2}$ vs. different $\mathrm{Au}^{3+}, \mathrm{Pt}^{4+}$ compositional ratios.

The effect of number of scan cycles during the CV deposition process on the size and morphology of Pt-Au nanoparticles were also discussed. The results had shown that the intensities of the nanoparticles increased with the increase of the number of scan cycles from 3 to 10 cycles. However, when the number of scan cycles increased to 10 cycles, nanoparticles with diameter lager than $20 \mathrm{~nm}$ were appeared, and the nanoparticles became non-uniform. (Figure 3A-C). Then the catalytic reduction to $\mathrm{H}_{2} \mathrm{O}_{2}$ was investigated. As shown in Figure 3D, the reduction peak current of $\mathrm{H}_{2} \mathrm{O}_{2}$ firstly increased from two to five cycles, and then decreased as the number of scan cycles further increased. The highest reduction peak current of $\mathrm{H}_{2} \mathrm{O}_{2}$ was obtained at five cycles. The phenomenon might be because that although higher intensities could provide more catalytic active sites, surface area might decrease on account of an exceedingly larger diameter of the nanoparticles. Thus, five cycles was adopted.

In this experiment, the effects of scan rate were also evaluated. As the result shown in Figure 4, the homogeneous Pt-Au bimetallic NPs with high catalytic activity towards the reduction of $\mathrm{H}_{2} \mathrm{O}_{2}$ were obtained when the scan rate was $100 \mathrm{mV} \cdot \mathrm{s}^{-1}$. Hence, the optimal scan rate was chosen as $100 \mathrm{mV} \cdot \mathrm{s}^{-1}$. 

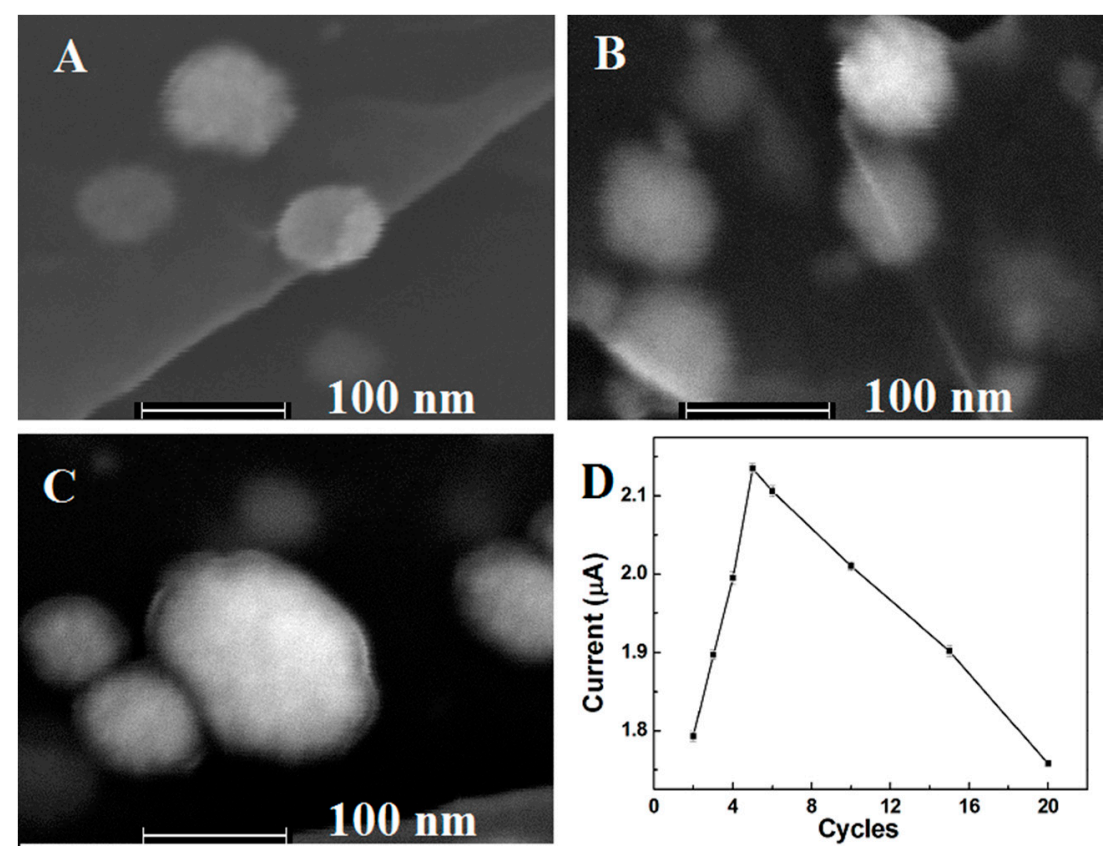

Figure 3. FESEM images of Pt-Au/rGSs hybrid films with different number of scan cycles: (A) 3 cycles; (B) 5 cycles and (C) 10 cycles, at the scan rate of $100 \mathrm{mV} \cdot \mathrm{s}^{-1}$; (D) plots of the peak current for the Pt-Au/rGSs/GCE in the presence of $0.1 \mathrm{mM} \mathrm{H}_{2} \mathrm{O}_{2}$ vs. different number of electrodeposition scan cycles.
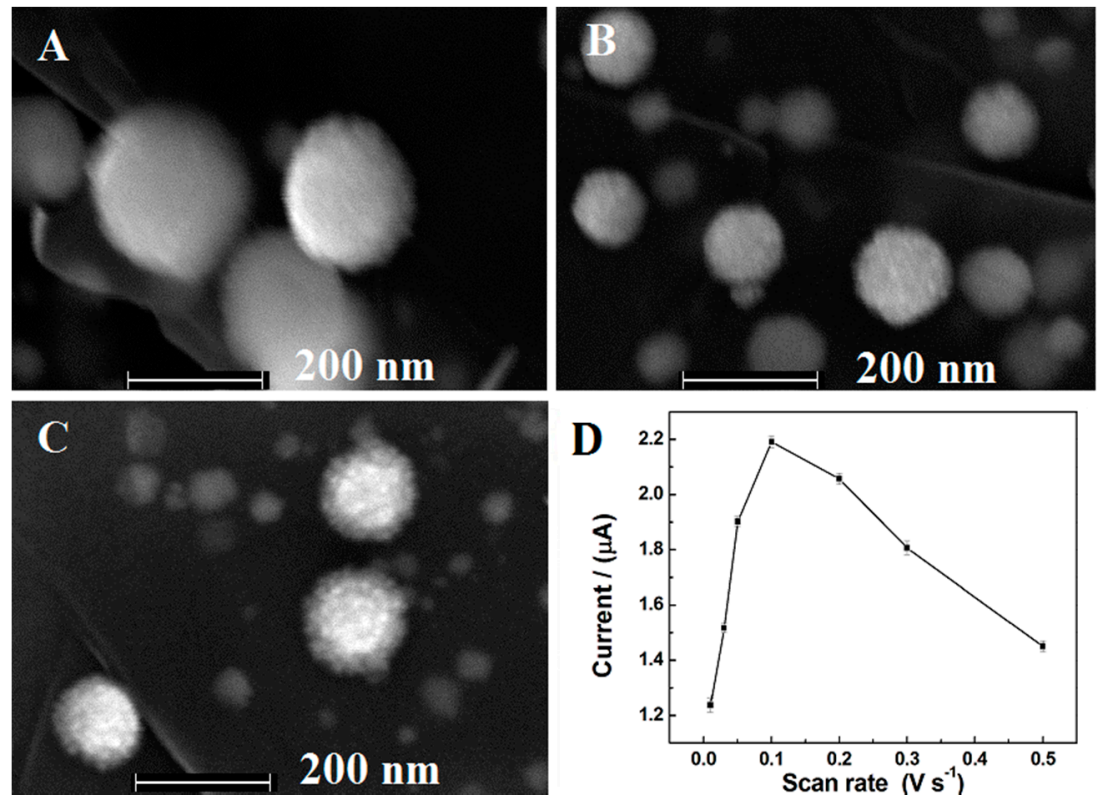

Figure 4. FESEM images of Pt-Au/rGSs hybrid films with different scan rates: (A) $50 \mathrm{mV} \cdot \mathrm{s}^{-1}$; (B) $100 \mathrm{mV} \cdot \mathrm{s}^{-1}$ and $(\mathbf{C}) 500 \mathrm{mV} \cdot \mathrm{s}^{-1}$; (D) plots of the peak current for the Pt-Au/rGSs/GCE in the presence of $0.1 \mathrm{mM} \mathrm{H}_{2} \mathrm{O}_{2}$ vs. different electrodeposition scan rates.

\subsection{Electrochemical Performances of the Pt-Au/rGSs/GCE towards $\mathrm{H}_{2} \mathrm{O}_{2}$}

Cyclic voltammetry responses of $0.1 \mathrm{mM} \mathrm{H}_{2} \mathrm{O}_{2}$ in $0.1 \mathrm{M} \mathrm{pH} 7.4 \mathrm{PBS}$ at different electrodes had been shown in Figure 5. After the addition of $0.1 \mathrm{mM} \mathrm{H}_{2} \mathrm{O}_{2}$, there was no observable reduction peak current on the bare and rGSs modified GCE, indicating that $\mathrm{H}_{2} \mathrm{O}_{2}$ could not be reduced at bare and 
rGSs modified GCE. In contrast, as shown in Figure 5, the reduction peak currents of $0.1 \mathrm{mM} \mathrm{H}_{2} \mathrm{O}_{2}$ on the differently modified electrodes increased as the following orders: Au/GCE $<\mathrm{Pt} / \mathrm{GCE}<$ $\mathrm{Pt} / \mathrm{rGSs} / \mathrm{GCE}<\mathrm{Pt}-\mathrm{Au} / \mathrm{GCE}<\mathrm{Pt}-\mathrm{Au} / \mathrm{rGSs} / \mathrm{GCE}$. Larger current density and earlier reduction peak potential were obtained on the Pt-Au/rGSs/GCE than the other modified electrodes, confirming the excellent electrocatalytic activity of Pt-Au/rGSs/GCE towards $\mathrm{H}_{2} \mathrm{O}_{2}$ reduction. Besides, it was also worth recognizing that the reduction peak potential of Pt-Au/rGSs/GCE was between $0.3 \mathrm{~V}$ and $0 \mathrm{~V}$, which was much higher than the previous reports. For instance, in the study of Meng, the potential range of the reduction of $\mathrm{H}_{2} \mathrm{O}_{2}$ was between $0 \mathrm{~V}$ and $-0.4 \mathrm{~V}$ on the nanoporous gold modified GCE [29]. Similarly, the Pt-Au/G-CNT/GCE constructed by Lu's groups displayed a reduction peak current around $-0.47 \mathrm{~V}$ [26]. The high reduction potential in this work suggested the Pt-Au/rGSs film had a high catalytic activity to $\mathrm{H}_{2} \mathrm{O}_{2}$ reduction. The excellent performance of Pt-Au/rGSs/GCE could be attributed to the tremendous improvement of the electrocatalytic and sensing performance of Pt in the presence of $\mathrm{Au}$ [30]. Besides, Pt-Au bimetallic NPs tended to be embedded in the rGSs homogeneously (Figure 2), which might help to facilitate the charge-transfer and mass-transfer processes. Therefore, Pt-Au/rGSs/GCE might have good performance in catalysis.

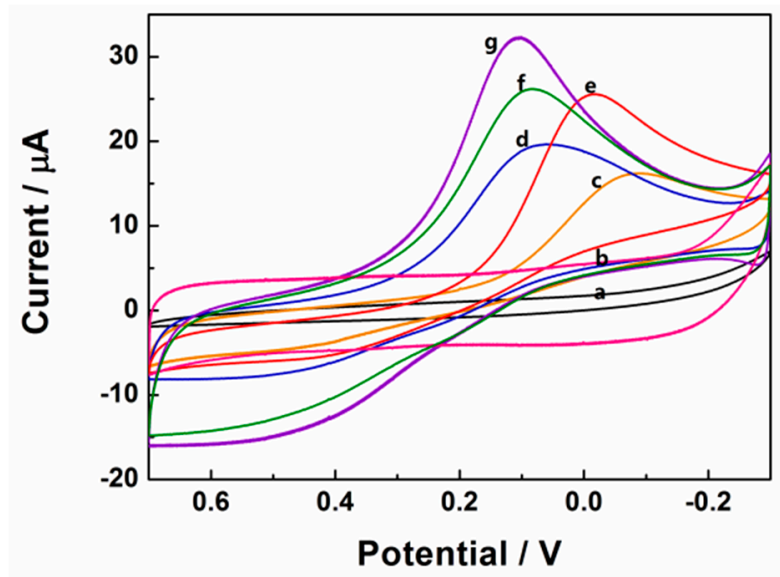

Figure 5. Cyclic voltammograms of (a) bare GCE; (b) $\mathrm{rGSs} / \mathrm{GCE}$; (c) $\mathrm{Au} / \mathrm{GCE}$; (d) $\mathrm{Pt} / \mathrm{GCE}$; (e) Pt-Au/GCE and (f) Pt/rGSs/GCE; (g) Pt-Au/rGSs/GCE in $0.1 \mathrm{M}$ PBS $(\mathrm{pH}=7.4)$ containing $0.1 \mathrm{mM} \mathrm{H} \mathrm{O}_{2}$ at a scan rate of $100 \mathrm{mV} \cdot \mathrm{s}^{-1}$.

\subsection{Amperometric Response and Calibration Curve for $\mathrm{H}_{2} \mathrm{O}_{2}$ Detection}

Figure $6 \mathrm{~A}$ shows a current-time curve of Pt-Au/rGSs/GCE with successive addition of $\mathrm{H}_{2} \mathrm{O}_{2}$ with different concentrations at an optimal potential of $0 \mathrm{~V}$. The current increased linearly along with the addition of $\mathrm{H}_{2} \mathrm{O}_{2}$ in the range from $1 \mu \mathrm{M}$ to $1.78 \mathrm{mM}$ and $1.78 \mathrm{mM}$ to $16.8 \mathrm{mM}$. Furthermore, the detection limit based on the signal to noise ratio $(\mathrm{S} / \mathrm{N})$ of 3 was calculated as low as $0.31 \mu \mathrm{M}$. The linear equations were $i=-0.052+6.168 C ; i=6.125+3.359 C(i$ in $\mu \mathrm{A}, C$ in $\mathrm{mM})$, with the correlation coefficient of 0.997 and 0.998 respectively (as shown in Figure 6B). The comparisons of analytical performance of the proposed sensor with other published $\mathrm{H}_{2} \mathrm{O}_{2}$ sensors had been displayed in Table 1. The results had revealed that the $\mathrm{H}_{2} \mathrm{O}_{2}$ sensor herein had comparative or even better advantages in lower detection limit and wider linearity range than several sensors reported recently. The higher sensitivity and wider linearity of this $\mathrm{H}_{2} \mathrm{O}_{2}$ sensor could be attributed to the addition of $\mathrm{Au}$, 
which could effectively improve the electrocatalytic activity of $\mathrm{Pt}$, especially the poisoning by adsorbed intermediates due to structure-induced promotional effects [22]. Furthermore, the addition of rGSs could increase the surface area and provide more active sites for the loading of $\mathrm{H}_{2} \mathrm{O}_{2}$.

A

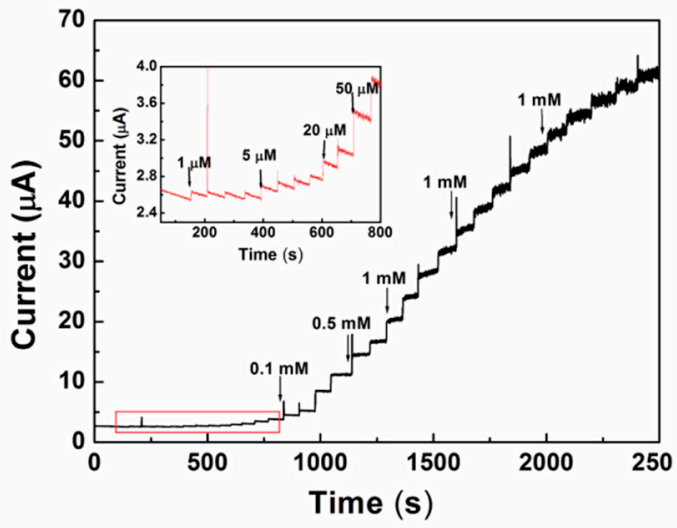

B

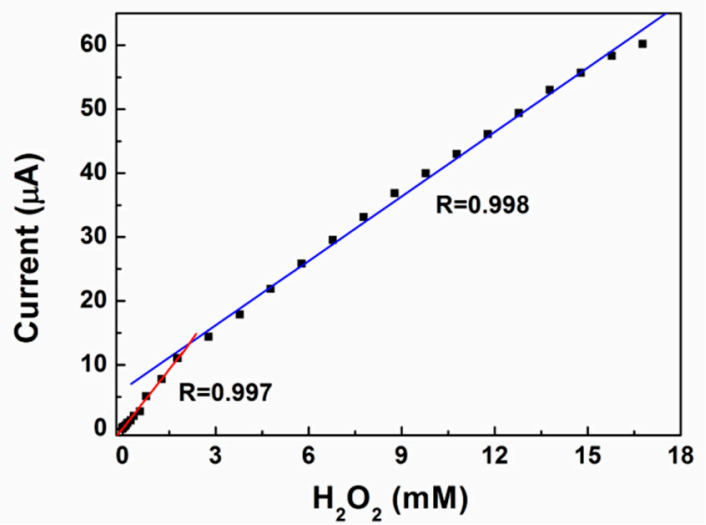

Figure 6. (A) Current-time response curve for successive injection of $\mathrm{H}_{2} \mathrm{O}_{2}$ at $\mathrm{Pt}-\mathrm{Au} / \mathrm{rGSs} / \mathrm{GCE}$ measured at $0 \mathrm{~V}$. Inset: Magnified image of the region in the rectangle; (B) Calibration curves of response current vs. $\mathrm{H}_{2} \mathrm{O}_{2}$ concentration at $\mathrm{Pt}-\mathrm{Au} / \mathrm{rGSs} / \mathrm{GCE}$.

Table 1. Comparisons of analytical performance of various $\mathrm{H}_{2} \mathrm{O}_{2}$ sensors.

\begin{tabular}{ccccc}
\hline Types of Electrode & Detection Potential $(\mathbf{V})$ & Linear Range $(\boldsymbol{\mu M})$ & Detection Limit $(\boldsymbol{\mu M})$ & Reference \\
\hline PDDA/t-MWCNT-Pt/GCE & -0.1 & $0.001-8$ & 0.27 & {$[21]$} \\
Pt-Au/G-CNTs/GCE & -0.47 & $0.002-8.561$ & 0.6 & {$[26]$} \\
Pt-CNT/GCE & -0.1 & $0.005-25$ & 1.5 & {$[31]$} \\
Se/Pt/GCE & -0 & $0.01-15$ & 3.1 & {$[32]$} \\
Pt-Au/rGSs/GCE & 0 & $0.001-1.78 ; 1.78-16.8$ & 0.31 & This work \\
\hline
\end{tabular}

\subsection{Interference Study}

The effect of common interfering electroactive substances such as glucose, AA, UA and DA were assessed and presented in Figure 7. It could be seen that an obvious amperometric response appeared when $0.05 \mathrm{mM} \mathrm{H}_{2} \mathrm{O}_{2}$ was injected at the first time. In the contrary, glucose $(1 \mathrm{mM}), \mathrm{AA}(0.5 \mathrm{mM})$, UA $(0.5 \mathrm{mM})$ and DA $(0.5 \mathrm{mM})$ did not cause observable amperometric changes. When $0.05 \mathrm{mM} \mathrm{H}_{2} \mathrm{O}_{2}$ was added at the second time, the current changed proportionally even with the existence of the interferents, which indicated the proposed electrode had a superior selectivity to $\mathrm{H}_{2} \mathrm{O}_{2}$. As is well known, oxygen is another important interferent during the reduction process of $\mathrm{H}_{2} \mathrm{O}_{2}$. Thus, in most of the published researches, supporting electrolyte usually need to be deoxygenated by bubbling nitrogen for at least 20 min prior to each experiment section [29]. In this work, the reduction potential of $\mathrm{H}_{2} \mathrm{O}_{2}$ on $\mathrm{Pt}-\mathrm{Au} / \mathrm{rGSs} / \mathrm{GCE}$ was around $0 \mathrm{~V}$, which effectively avoided the interference of oxygen. Under this circumstance, the whole experiment in this study had been carried out without removing oxygen. All of the above results had indicated that the proposed $\mathrm{H}_{2} \mathrm{O}_{2}$ sensor could be used in vivo. 


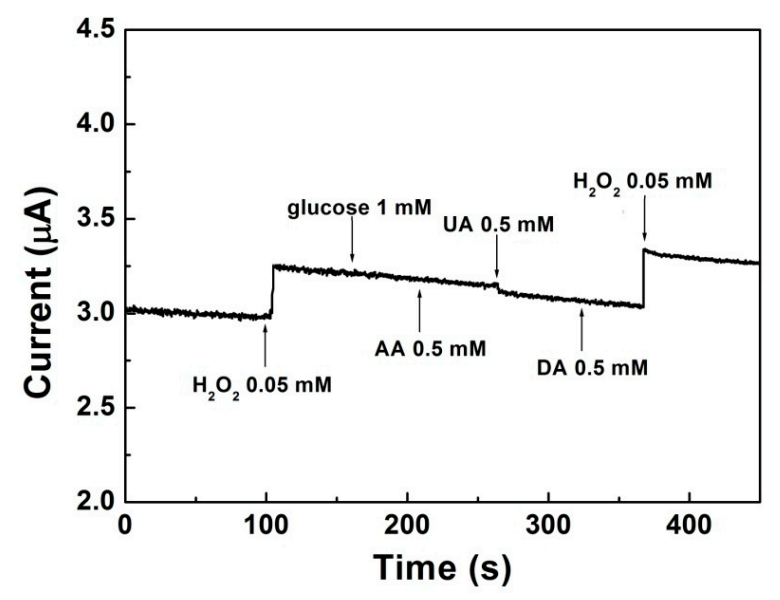

Figure 7. Current-time response curve at $\mathrm{Pt}-\mathrm{Au} / \mathrm{rGSs} / \mathrm{GCE}$ for successive injection of $\mathrm{H}_{2} \mathrm{O}_{2}$, glucose, AA, UA and DA in $0.1 \mathrm{M}$ PBS at $0 \mathrm{~V}$.

\subsection{Reproducibility and Stability}

The reproducibility and stability of $\mathrm{Pt}-\mathrm{Au} / \mathrm{rGSs} / \mathrm{GCE}$ were also investigated. The relative standard deviation (RSD) of the current signal for $0.1 \mathrm{mM} \mathrm{H}_{2} \mathrm{O}_{2}$ was less than $2.1 \%$ for six measurements at the same electrode. Besides, the RSD was less than $4.7 \%$ at six modified electrodes prepared at the same condition. The results suggested a good reproducibility of the proposed $\mathrm{H}_{2} \mathrm{O}_{2}$ sensor. After being stored in the refrigerator at $4{ }^{\circ} \mathrm{C}$ for two weeks, the modified electrode still remained $93.2 \%$ of its original response, indicating that the fabricated $\mathrm{H}_{2} \mathrm{O}_{2}$ sensor exhibited long-term stability.

\subsection{Determination of $\mathrm{H}_{2} \mathrm{O}_{2}$ Released from $\mathrm{PC} 12$ Cells}

Figure 8 displays the amperometric responses at bare GCE and $\mathrm{Pt}-\mathrm{Au} / \mathrm{rGSs} / \mathrm{GCE}$ in $0.1 \mathrm{M} \mathrm{PBS}$ containing PC 12 cells and $100 \mathrm{mM}$ glucose. The increased cathodic current was observed at the $\mathrm{Pt}-\mathrm{Au} / \mathrm{rGSs} / \mathrm{GC}$ electrode with the addition of $5 \mu \mathrm{g} \cdot \mathrm{mL}^{-1} \mathrm{LPS}$, which was reported to induce $\mathrm{H}_{2} \mathrm{O}_{2}$ production from the cells [33].

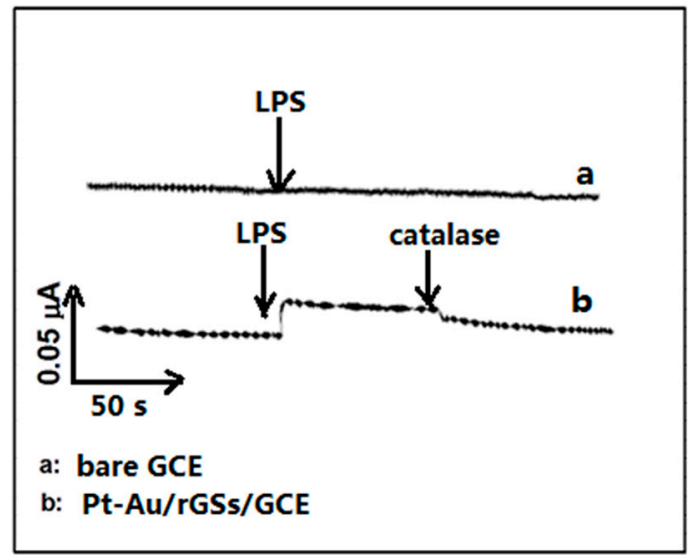

Figure 8. Amperometric responses at (a) bare GCE and (b) Pt-Au/rGSs/GCE in $0.1 \mathrm{M}$ PBS containing PC 12 cells at the potential of $0 \mathrm{~V}$ with the addition of $5 \mu \mathrm{g} \cdot \mathrm{mL}^{-1} \mathrm{LPS}$ and 200 units $\cdot \mathrm{mL}^{-1}$ catalase. 
Meanwhile, no response was attained at bare GCE with the same addition of LPS. After the injection of 200 unit $\cdot \mathrm{mL}^{-1}$ catalase, the reduction current decreased at the Pt-Au/rGSs/GCE. The phenomena demonstrated that the reduction current at $\mathrm{Pt}-\mathrm{Au} / \mathrm{rGSs} / \mathrm{GC}$ electrode was ascribed to the reduction of $\mathrm{H}_{2} \mathrm{O}_{2}$. These observations suggested the proposed electrode provided a promising alternative for the monitoring of $\mathrm{H}_{2} \mathrm{O}_{2}$ released from cells. Additionally, it could be potentially useful for further understanding of the role of oxidative stress in physiological and pathological processes.

\section{Conclusions}

In this study, Pt-Au bimetallic NPs were successfully synthesized on the rGSs modified GCE via a simple electrochemical deposition method. High dispersion and small particle size of the Pt-Au bimetallic NPs were achieved as respected by controlling the deposition conditions. Pt-Au/rGSs/GCE constructed upon optimal conditions exhibited high sensitivity and low-activation energy for the determination of $\mathrm{H}_{2} \mathrm{O}_{2}$. Wide linear ranges for the amperometric detection of $\mathrm{H}_{2} \mathrm{O}_{2}$ were respectively obtained from $1 \mu \mathrm{M}$ to $1.78 \mathrm{mM}$ and $1.78 \mathrm{mM}$ to $16.8 \mathrm{mM}$, with a detection limit as low as $0.31 \mu \mathrm{M}$. Furthermore, the Pt-Au/rGSs/GCE showed high selectivity of $\mathrm{H}_{2} \mathrm{O}_{2}$ in the presence of common co-existing compounds like glucose, UA, AA, DA and oxygen. Good reproducibility and stability were also displayed on the proposed electrode. In view of all the unique properties, the fabricated sensor is promising for the practical application in the real-time detection of $\mathrm{H}_{2} \mathrm{O}_{2}$ in vivo, providing an alternative method to figure out the role that oxidative stress plays in physiological and pathological processes.

\section{Acknowledgments}

Financial support from the National Basic Research Program of China (973 Program, No. 2015CB352100), Program for New Century Excellent Talents in University (No. NCET-13-0232), and the Fundamental Research Funds for the Central Universities (Huazhong University of Science and Technology, CXY13Q050) are greatly acknowledged. The Center of Analysis and Testing of Huazhong University of Science and Technology is thanked for its help in FESEM observation.

\section{Author Contributions}

All authors contributed significantly to this work. Qing Lu designed and guided the experiment; Guangxia $\mathrm{Yu}$ performed the experiment and wrote the manuscript; Weixiang $\mathrm{Wu}$ analyzed the data and revised the manuscript. Xiaoqi Pan cultured the PC 12 cells. Qiang Zhao and Xiaoyun Wei prepared the figures. All of the authors read and approved the final manuscript.

\section{Conflicts of Interest}

The authors declare no conflict of interest. 


\section{References}

1. Izawa, S.; Kono, K.; Mimura, K.; Kawaguchi, Y.; Watanabe, M.; Maruyama, T.; Fujii, $\mathrm{H} \mathrm{H}_{2} \mathrm{O}_{2}$ production within tumor microenvironment inversely correlated with infiltration of CD 56 (dim) NK cells in gastric and esophageal cancer: Possible mechanisms of NK cell dysfunction. Cancer Immunol. Immunother. 2011, 60, 1801-1810.

2. Youdim, K.A.; Joseph, J.A. A possible emerging role of phytochemicals in improving age-related neurological dysfunctions: A multiplicity of effects. Free Radic. Biol. Med. 2001, 30, 583-594.

3. Szatrowski, T.P.; Nathan, C.F. Production of large amounts of hydrogen peroxide by human tumor cells. Cancer Res. 1991, 51, 794-798.

4. Nagaraja, P.; Prakash, J.S.; Asha, S.C.; Bhaskara, B.L.; Kumar, S.A. Dibenzazepin hydrochloride as a new spectrophotometric reagent for determination of hydrogen peroxide in plant extracts. Environ. Monit. Assess. 2012, 184, 5983-5988.

5. Ning, R.; Lu, W.; Zhang, Y.; Qin, X.; Luo, Y.; Hu, J.; Asiri, A.M.; Al-Youbi, A.O.; Sun, X. Anovel strategy to synthesize au nanoplates and their application for enzymeless $\mathrm{H}_{2} \mathrm{O}_{2}$ detection. Electrochim. Acta 2012, 60, 13-16.

6. Abo, M.; Urano, Y.; Hanaoka, K.; Terai, T.; Komatsu, T.; Nagano, T. Development of a highly sensitive fluorescence probe for hydrogen peroxide. J. Am. Chem. Soc. 2011, 133, 10629-10637.

7. Hurdis, E.; Romeyn, Jr, H. Accuracy of determination of hydrogen peroxide by cerate oxidimetry. Anal. Chem. 1954, 26, 320-325.

8. Amatore, C.; Arbault, S.; Guille, M.; Lemaitre, F. Electrochemical monitoring of single cell secretion: Vesicular exocytosis and oxidative stress. Chem. Rev. 2008, 108, 2585-2621.

9. Wu, P.; Cai, Z.; Gao, Y.; Zhang, H.; Cai, C. Enhancing the electrochemical reduction of hydrogen peroxide based on nitrogen-doped graphene for measurement of its releasing process from living cells. Chem. Commun. 2011, 47, 11327-11329.

10. Rui, Q.; Komori, K.; Tian, Y.; Liu, H.; Luo, Y.; Sakai, Y. Electrochemical biosensor for the detection of $\mathrm{H}_{2} \mathrm{O}_{2}$ from living cancer cells based on $\mathrm{ZnO}$ nanosheets. Anal. Chim. Acta 2010, 670, $57-62$.

11. Luo, Y.; Liu, H.; Rui, Q.; Tian, Y. Detection of extracellular $\mathrm{H}_{2} \mathrm{O}_{2}$ released from human liver cancer cells based on $\mathrm{TiO}_{2}$ nanoneedles with enhanced electron transfer of cytochrome C. Anal. Chem. 2009, 81, 3035-3041.

12. Chen, K.J.; Chandrasekara Pillai, K.; Rick, J.; Pan, C.J.; Wang, S.H.; Liu, C.C.; Hwang, B.J. Bimetallic PtM (M = Pd, Ir) nanoparticle decorated multi-walled carbon nanotube enzyme-free, mediator-less amperometric sensor for $\mathrm{H}_{2} \mathrm{O}_{2}$. Biosens. Bioelectron. 2012, 33, 120-127.

13. Yu, Y.; Sun, Q.; Liu, X.; Wu, H.; Zhou, T.; Shi, G. Size-controllable gold-platinum alloy nanoparticles on nine functionalized ionic-liquid surfaces and their application as electrocatalysts for hydrogen peroxide reduction. Chem. Eur. J. 2011, 17, 11314-11323.

14. Tsai, T.-H.; Thiagarajan, S.; Chen, S.-M. Green synthesized au-ag bimetallic nanoparticles modified electrodes for the amperometric detection of hydrogen peroxide. J. Appl. Electrochem. 2010, 40, 2071-2076. 
15. Niu, X.; Chen, C.; Zhao, H.; Chai, Y.; Lan, M. Novel snowflake-like Pt-Pd bimetallic clusters on screen-printed gold nanofilm electrode for $\mathrm{H}_{2} \mathrm{O}_{2}$ and glucose sensing. Biosens. Bioelectron. 2012, $36,262-266$.

16. Xu, C.; Liu, Y.; Su, F.; Liu, A.; Qiu, H. Nanoporous ptag and ptcu alloys with hollow ligaments for enhanced electrocatalysis and glucose biosensing. Biosens. Bioelectron. 2011, 27, 160-166.

17. Wang, H.; Bo, X.; Bai, J.; Wang, L.; Guo, L. Electrochemical applications of platinum-palladium alloy nanoparticles/large mesoporous carbon. J. Electroanal. Chem. 2011, 662, 281-287.

18. Liu, A.; Geng, H.; Xu, C.; Qiu, H. A three-dimensional hierarchical nanoporous pdcu alloy for enhanced electrocatalysis and biosensing. Anal. Chim. Acta 2011, 703, 172-178.

19. Rajkumar, M.; Thiagarajan, S.; Chen, S.-M. Electrochemical fabrication of Rh-Pd particles and electrocatalytic applications. J. Appl. Electrochem. 2011, 41, 663-668.

20. Janasek, D.; Vastarella, W.; Spohn, U.; Teuscher, N.; Heilmann, A. Ruthenium/rhodium modified gold electrodes for the amperometric detection of hydrogen peroxide at low potentials. Anal. Bioanal. Chem. 2002, 374, 1267-1273.

21. You, J.-M.; Kim, D.; Jeon, S. Electrocatalytic reduction of $\mathrm{H}_{2} \mathrm{O}_{2}$ by pt nanoparticles covalently bonded to thiolated carbon nanostructures. Electrochim. Acta 2012, 65, 288-293.

22. Li, C.L.; Wang, H.J.; Yamauchi, Y. Electrochemical deposition of mesoporous Pt-Au alloy films in aqueous surfactant solutions: Towards a highly sensitive amperometric glucose sensor. Chem. Eur. J. 2013, 19, 2242-2246.

23. Geim, A.K. Graphene: Status and prospects. Science 2009, 324, 1530-1534.

24. Zhang, S.; Shao, Y.; Liao, H.; Liu, J.; Aksay, I.A.; Yin, G.; Lin, Y. Graphene decorated with PtAu alloy nanoparticles: Facile synthesis and promising application for formic acid oxidation. Chem. Mater. 2011, 23, 1079-1081.

25. Tang, L.; Wang, Y.; Li, Y.; Feng, H.; Lu, J.; Li, J. Preparation, structure, and electrochemical properties of reduced graphene sheet films. Adv. Funct. Mater. 2009, 19, 2782-2789.

26. Lu, D.; Zhang, Y.; Lin, S.; Wang, L.; Wang, C. Synthesis of ptau bimetallic nanoparticles on graphene-carbon nanotube hybrid nanomaterials for nonenzymatic hydrogen peroxide sensor. Talanta 2013, 112, 111-116.

27. Xing, Y. Synthesis and electrochemical characterization of uniformly-dispersed high loading $\mathrm{Pt}$ nanoparticles on sonochemically-treated carbon nanotubes. J. Phys. Chem. B 2004, 108, 19255-19259.

28. Yamauchi, Y.; Tonegawa, A.; Komatsu, M.; Wang, H.; Wang, L.; Nemoto, Y.; Suzuki, N.; Kuroda, K. Electrochemical synthesis of mesoporous Pt-Au binary alloys with tunable compositions for enhancement of electrochemical performance. J. Am. Chem. Soc. 2012, 134, 5100-5109.

29. Meng, F.H.; Yan, X.L.; Liu, J.G.; Gu, J.; Zou, Z.G. Nanoporous gold as non-enzymatic sensor for hydrogen peroxide. Electrochim. Acta 2011, 56, 4657-4662.

30. Zhong, W.H.; Liu, Y.X.; Zhang, D.J. Theoretical study of methanol oxidation on the PtAu (111) bimetallic surface: CO pathway vs. Non-CO pathway. J. Phys. Chem. C 2012, 116, 2994-3000.

31. Wen, Z.; Ci, S.; Li, J. Pt nanoparticles inserting in carbon nanotube arrays: Nanocomposites for glucose biosensors. J. Phys. Chem. C 2009, 113, 13482-13487. 
32. Li, Y.; Zhang, J.-J.; Xuan, J.; Jiang, L.-P.; Zhu, J.-J. Fabrication of a novel nonenzymatic hydrogen peroxide sensor based on Se/Pt nanocomposites. Electrochem. Commun. 2010, 12, $777-780$.

33. Kruzel, M.L.; Actor, J.K.; Radak, Z.; Bacsi, A.; Saavedra-Molina, A.; Boldogh, I. Lactoferrin decreases lps-induced mitochondrial dysfunction in cultured cells and in animal endotoxemia model. Innate Immun. 2010, 16, 67-79.

(C) 2015 by the authors; licensee MDPI, Basel, Switzerland. This article is an open access article distributed under the terms and conditions of the Creative Commons Attribution license (http://creativecommons.org/licenses/by/4.0/). 